\title{
Cervical Spinal Stenosis and Risk of Pulmonary Dysfunction: Case Control Study
}

\author{
Post graduate Student Esraa Hammadi Fahad ${ }^{1}$, Zainab H. Hashim ${ }^{1}$, Ihssan S. Nema ${ }^{1}$ \\ ${ }^{1}$ Dept. of Physiology, College of Medicine, Al-Nahrain University, Baghdad, Iraq.
}

\begin{abstract}
Background: Cervical spinal stenosis is well-defined as debility in the volume of the spinal canal. Consequently, distracting in the descending neural pathways at any level in the cervical spine lead to impaired smooth and effective breathing under normal conditions .

Objective: To assess the effect of cervical spinal stenosis (C5and above) on pulmonary function tests, to assess the sensitivity and specificity of pulmonary function tests in patient with cervical spinal stenosis(C5 and above).

Methods: This is a case-control study which included 40 patients divided into two groups 30 females and 10 males patients with cervical spinal stenosis ( $\mathrm{C} 5$ and above) and 60 healthy volunteers with body mass index $<30\left(\mathrm{Kg} / \mathrm{m}^{2}\right)$. Pulmonary function tests has been done for all subjects.

Results: The results demonstrate the comparison between all patients and controls show that VC EX\% ,FEV1\% ,FVC\% ,PEF\% ,MVV\% , were significantly lower in patients in comparison to control groups as well as $\mathrm{VC} \mathrm{EX} \mathrm{\% ,FEV1 \% ,FVC} \mathrm{\%} \mathrm{were} \mathrm{significantly} \mathrm{lower} \mathrm{in} \mathrm{male} \mathrm{patients} \mathrm{in} \mathrm{comparison} \mathrm{to} \mathrm{controls} \mathrm{and}$ in female patients as compared to female controls and MVV\% were significantly lower in female patients in comparison to male patients, while no significant difference has been identified between patients and controls regarding age ,weight, height , BMI,VC IN\% and FEV1\FVC \%. Sensitivity and specificity and cut off value for pulmonary function tests parameters show FEV $1 \%$ is the highest specificity and sensitivity.

Conclusion: The respiratory dysfunction that is established in patients with cervical spinal stenosis usually subclinical not overt defect that compromised respiration, this pulmonary dysfunction is a type of restrictive lung disease since phrenic nerve is affected. . FEVI\% is most essential among other parameters of spirometry in patients with cervical spinal stenosis.
\end{abstract}

Keywords: Cervical spinal stenosis, pulmonary function tests, Spirometry

\section{Introduction}

Stenosis of cervical spine is well-defined as a waning in the volume of the canal of spine. ${ }^{[1]}$ Even though stenosis of the central canal can transpire everywhere alongside the length of the spine, this condition is deliberated more threatening with greater forthcoming for serious neurological sequelae when it occurs in the cervical spine. ${ }^{[2,3,4]}$

Degenerative cervical myelopathy DCM is judged to be the most common cord of spine illness, and is predictable to have an increasing prevalence with the aging population in the work world. ${ }^{[5]}$
Respiratory function has been well-ordered by the phrenic (C3-5) nerves, the intercostal (T2-10) nerves, and autonomic nerve, especially the sympathetic (T1L3) nerves. Consequently, distracting in the descending neural pathways at any level in the cervical spine lead to impaired smooth and effective breathing under normal conditions. The effect might lead to the worsening of pulmonary function even if the impairment of neural function was subclinical. $[6,7,8]$

\section{Method}

This is case control, nonrandomized, single-center study evaluating pulmonary function tests in patients 
with cervical spinal stenosis (C5 and above) who attend orthopedic and neurosurgical consultations in ALImamian AL-Kadhymiyian medical city during period from November 2018 to May 2019.

40 patients divided into two groups 30 females and 10 males patients with cervical spinal stenosis (C5 and above) with age range from (25 to 70 ) years and body mass index $<30\left(\mathrm{Kg} / \mathrm{m}^{2}\right)$. The duration of their illness ranges from ( 1 to 24$)$ months.

All patients were clinically examined and diagnosed by MRI with or without CT scanning and X ray of the cervical spine to determine the level of compression. The diagnosis was supported by trans cranial magnetic stimulation (TMS) technique. Smokers and (x) smokers for at least six months, systemic disease known to cause peripheral neuropathies (Diabetes Mellitus), Spinal tumor, chronic pulmonary disease. Central obesity (WC $\geq 94 \mathrm{~cm}$ for men and $\geq 80 \mathrm{~cm}$ for women), ${ }^{[9]}$ or waistto-hip ratio (WHR) $\geq 0.90$ in men and $\geq 0.85$ in women and a WHTR of $>0.50^{[9]}, \mathrm{BMI} \geq 30\left(\mathrm{Kg} / \mathrm{m}^{2}\right)$ had been excluded from the study. Sixty apparently healthy peoples aged and sex matched nonsmoker nor centrally obese as volunteers control group thirty males and thirty females.Their age ranges from (30-75) with BMI $<30$ $\left(\mathrm{Kg} / \mathrm{m}^{2}\right)$.

Pulmonary function tests have been done for all subjects, the result was presented on a discrete paper in a special form. The tests incorporated the following: Vital capacity in inspiration VC IN, Vital capacity in expiration VC EX, Forced expiratory volume in $1^{\text {st }}$ second FEV1, Forced vital capacity FVC, Forced expiratory flow between 25-75 of the FVC or Forced mid -flow (FEF25-75\%,FMF), Peak expiratory flow rate PEFR, Mean voluntary ventilation (MVV), ratio of FEV1 to FVC (FEV1/FVC). Predicted values of the Spiro metric parameters were based on the patient's height, age, and sex. The percentage of predicted values was used for comparison.

$$
\% \text { predicted }=\text { measured } \div \text { predicted }^{[10]}
$$

The study approved by the Institutional Review Board (IRB) of the college of Medicine, Al-Nahrain University and informed consents were obtained from all the participants.

\section{Statistical analysis}

Statistical analysis was performed with SPSS V23. (statistical package for social sciences) and also Excel 2007 programs. Data analysis was done using t-test and the values were considered statistically significant when $\mathrm{p}$-value $<0.05$. For each parameter the sensitivity and specifity by ROC analysis.

\section{Results}

Table 1 shows that VC EX\%, FEV1\%, FVC\%, $\mathrm{PEF} \%, \mathrm{MVV} \%$, were significantly lower in patients in comparison to control groups $(\mathrm{P}<0.001),(\mathrm{P}<0.001)$, $(\mathrm{P}<0.001), \quad(\mathrm{p}=0.042), \quad(\mathrm{P}=0.037)$, respectively .While there were no significant difference has been identified between patients and controls regarding age,weight, height, BMI,VC IN\% and FEV $1 \backslash \mathrm{FVC} \%$.

Table (1): Comparison of data between all patients and all controls by unpaired t test

\begin{tabular}{|l|l|l|l|}
\hline Parameter & $\begin{array}{l}\text { All Patients } \\
\mathbf{N}=\mathbf{4 0} \\
\text { Mean } \pm \text { SD }\end{array}$ & $\begin{array}{l}\text { All Controls } \\
\mathbf{N}=\mathbf{6 0} \\
\text { Mean } \pm \text { SD }\end{array}$ & P value \\
\hline Age $(\mathrm{yr})$ & $50.05+12.5$ & $49.92+11.04$ & 0.955 \\
\hline Weight $(\mathrm{kg})$ & $67.05+8.04$ & $70.42+9.36$ & 0.066 \\
\hline Height $(\mathrm{cm})$ & $159.93+8.99$ & $162.28+9.49$ & 0.217 \\
\hline BMI $(\mathrm{kg} / \mathrm{m} 2)$ & $26.21+2.29$ & $26.71+2.29$ & 0.282 \\
\hline VC IN\% & $90.48+14.35$ & $94.33+13.58$ & 0.177 \\
\hline VC EX\% & $79.23+11.24$ & $90.86+11.8$ & $<\mathbf{0 . 0 0 1}$ \\
\hline FEV $1 \%$ & $89.16+15.59$ & $105.53+14.04$ & $<\mathbf{0 . 0 0 1}$ \\
\hline FVC\% & $77.26+13.1$ & $90.56+12.69$ & $<\mathbf{0 . 0 0 1}$ \\
\hline PEF\% & $85.21+14.82$ & $93.21+21.32$ & $\mathbf{0 . 0 4 2}$ \\
\hline FEV1 1 FVC\% & $95.72+4.08$ & $96.56+3.89$ & 0.302 \\
\hline MVV\% & $98.42+16.77$ & $106.14+18.55$ & $\mathbf{0 . 0 3 7}$ \\
\hline
\end{tabular}


Table (2) shows that VC EX \%, FEV1\%, FVC \% were significantly lower in male patients in comparison to controls $(\mathrm{P}=0.001)(\mathrm{P}=0.004),(\mathrm{P}=0.002)$ respectively. While there were no significant difference has been identified between male patients and male controls regarding age, weight, height, BMI, VC IN \%, PEF\%, FEV1 $\backslash F V C \%$, and $\mathrm{MVV} \%$.

Table (2): Comparison of data between male patients and male controls by unpaired $t$ test

\begin{tabular}{|c|c|c|c|}
\hline Parameter & $\begin{array}{l}\text { Male Patients } \\
\text { N=10 } \\
\text { Mean } \pm \text { SD }\end{array}$ & $\begin{array}{l}\text { Male Controls } \\
\text { N=30 } \\
\text { Mean } \pm \text { SD }\end{array}$ & $P$ value \\
\hline Age (yr) & $55.5+12.07$ & $52.9+11.38$ & 0.541 \\
\hline Weight (kg) & $75.0+6.38$ & $73.87+10.46$ & 0.749 \\
\hline Height (cm) & $170.5+5.97$ & $168.4+7.89$ & 0.446 \\
\hline BMI (kg/m2) & $25.78+1.44$ & $25.94+2.43$ & 0.850 \\
\hline VC IN\% & $84.7+14.11$ & $89.94+12.36$ & 0.269 \\
\hline VC EX\% & $74.71+7.51$ & $88.32+11.71$ & 0.001 \\
\hline FEV1\% & $88.18+12.5$ & $105.81+16.36$ & 0.004 \\
\hline $\mathrm{FVC} \%$ & $73.51+9.75$ & $88.9+13.08$ & 0.002 \\
\hline PEF\% & $89.59+14.02$ & $92.1+16.41$ & 0.667 \\
\hline FEV $1 \backslash F V C \%$ & $95.36+3.11$ & $95.9+4.33$ & 0.715 \\
\hline MVV\% & $119.11+11.67$ & $119.2+15.24$ & 0.987 \\
\hline
\end{tabular}

Table (3) shows that: VC EX\%, FEV1\%, FVC \% were significantly lower in female patients in comparison to female controls $(p<0.001),(p<0.001),(p<0.001)$ respectively. While there were no significant difference has been identified between female patients and female controls regarding age, weight, height, BMI, VC IN\%, PEF\%, FEV1〉 $\mathrm{FVC} \%, \mathrm{MVV} \%$.

Table (3): Comparison of data between female patients and female controls by unpaired t test

\begin{tabular}{|c|c|c|c|}
\hline Parameter & $\begin{array}{l}\text { Female Patients } \\
\mathrm{N}=\mathbf{3 0} \\
\text { Mean } \pm \text { SD }\end{array}$ & $\begin{array}{l}\text { Female Controls } \\
\text { N=30 } \\
\text { Mean } \pm \text { SD }\end{array}$ & $P$ value \\
\hline Age (yr) & $48.23+12.3$ & $46.93+10$ & 0.655 \\
\hline Weight (kg) & $64.4+6.73$ & $66.97+6.65$ & 0.143 \\
\hline Height (cm) & $156.4+6.8$ & $156.17+6.59$ & 0.893 \\
\hline BMI (kg/m2) & $26.35+2.52$ & $27.48+1.86$ & 0.051 \\
\hline VC IN\% & $92.4+14.14$ & $98.73+13.49$ & 0.082 \\
\hline VC EX\% & $80.74+11.96$ & $93.4+11.53$ & $<0.001$ \\
\hline FEV $1 \%$ & $89.48+16.67$ & $105.25+11.54$ & $<0.001$ \\
\hline $\mathrm{FVC} \%$ & $78.5+13.96$ & $92.21+12.29$ & $<0.001$ \\
\hline $\mathrm{PEF} \%$ & $83.74+15.02$ & $94.32+25.55$ & 0.056 \\
\hline FEV $1 \backslash F V C \%$ & $95.84+4.39$ & $97.22+3.33$ & 0.177 \\
\hline MVV\% & $91.52+11.79$ & $93.08+10.72$ & 0.594 \\
\hline
\end{tabular}


Table (4) shows that : weight, height, MVV\% were significantly lower in female patients in comparison to male patients, $(\mathrm{p}<0.001)$. While there were no significant difference has been identified between male and female patients regarding age, BMI, VC IN\%,VC EX\%, FEV1\%, FVC \%, PEF\%, FEV1\FVC\%.

Table (4): Comparison of data between male and female patients by unpaired $t$ test

\begin{tabular}{|c|c|c|c|}
\hline Parameter & $\begin{array}{l}\text { Male Patients } \\
\mathbf{N}=10 \\
\text { Mean } \pm \text { SD }\end{array}$ & $\begin{array}{l}\text { Female Patients } \\
\mathbf{N}=\mathbf{3 0} \\
\text { Mean } \pm \text { SD }\end{array}$ & $P$ value \\
\hline Age (yr) & $55.5+12.07$ & $48.23+12.3$ & 0.112 \\
\hline Weight (kg) & $75.0+6.38$ & $64.4+6.73$ & $<0.001$ \\
\hline Height (cm) & $170.5+5.97$ & $156.4+6.8$ & $<0.001$ \\
\hline BMI (kg/m2) & $25.78+1.44$ & $26.35+2.52$ & 0.507 \\
\hline VC IN\% & $84.7+14.11$ & $92.4+14.14$ & 0.144 \\
\hline VC EX\% & $74.71+7.51$ & $80.74+11.96$ & 0.144 \\
\hline FEV1\% & $88.18+12.5$ & $89.48+16.67$ & 0.823 \\
\hline FVC $\%$ & $73.51+9.75$ & $78.5+13.96$ & 0.303 \\
\hline PEF\% & $89.59+14.02$ & $83.74+15.02$ & 0.286 \\
\hline FEV $1 \backslash \mathrm{FVC} \%$ & $95.36+3.11$ & $95.84+4.39$ & 0.747 \\
\hline MVV\% & $119.11+11.67$ & $91.52+11.79$ & $<0.001$ \\
\hline
\end{tabular}

Table (5) shows:

Cutoff value of VCIN\%,VCEX\%,FEV1\%,FVC\%,PEF\%,FEV1\FVC\%,MVV\%

In ROC were estimated and consequently the sensitivity and specificity were evaluated FEV $1 \%$ show the highest specificity and sensitivity.

Table (5): Area under curve, sensitivity, specificity and cutoff value for pulmonary function tests parameter

\begin{tabular}{|l|l|l|l|l|}
\hline Parameters & AUC & Sensitivity & Specificity & Cut-off value \\
\hline VC IN\% & 0.573 & $53.3 \%$ & $55.0 \%$ & 91.25 \\
\hline VCEX\% & 0.779 & $70.0 \%$ & $70.0 \%$ & 82.2 \\
\hline FEV1\% & 0.813 & $75.0 \%$ & $75.0 \%$ & 95.1 \\
\hline FVC $\%$ & 0.784 & $66.7 \%$ & $67.5 \%$ & 82.6 \\
\hline PEF\% & 0.623 & $56.7 \%$ & $60.0 \%$ & 86.75 \\
\hline FEV1\FVC $\%$ & 0.554 & $56.7 \%$ & $57.5 \%$ & 97.02 \\
\hline MVV\% & 0.624 & $61.7 \%$ & $62.5 \%$ & 100.06 \\
\hline
\end{tabular}




\section{Discussion}

Patients with compressive cervical spinal stenosis designated by the spirometric data as mild but considerable impairment of respiratory function. Lesion in the cervical spinal cord can lead to respiratory insufficiency by disturbing the descending pathways. ${ }^{[11]}$

The present study show no significant differences between age ,height, weight of patient and control groups and this resembling to study done by (Toyoda et al). ${ }^{[1]}$

Pulmonary functions endure the major biologic variable that is affected by aging. There has been great individual variation in the extent of the aging process in the lungs. Even in individuals with good health, there are quantifiable decrements in function of the respiratory system with age. ${ }^{[12]}$

The weight is another factor that have been with adverse effect on lung function which showed by various studies. ${ }^{[13,14]}$ Congregation validation designates that the association between increase in weight and both lung volume and lung function, the lung volume and capacity that reduced in overweight subjects compared with healthy subjects. ${ }^{[13]}$

The present study showed that $\mathrm{VC} \%, \mathrm{FVC} \%$, $\mathrm{PEF} \%, \mathrm{FEV} 1 \%, \mathrm{MVV} \%$ of patients were significantly lower than controls.

The probable explanation for the pathomechanism of this may embrace that the phrenic nerve has been partial injured, decrease in the strength of the respiratory muscle, and the intercostal muscle tone loss. In healthy individuals the parasympathetic activity has been prime, so in the mild respiratory dysfunction imbalance of the autonomic nervous system has been arise. ${ }^{[11]}$ Consequently, sympathetic activity has been predominant in the chronic compression of the cervical spinal cord in addition to diminish in peripheral airway resistance.

The present study show no significant difference between FEV1 $1 \mathrm{FVC} \%$ of patients and controls and this agreement with Bhagavatula et al, ${ }^{[10]}$ since in our study the result of spirometric data involve normal and restrictive lung function values, so according to study done by Pellegrino et $\mathrm{a}^{[15]}$ which state that restrictive ventilation disorders are characterized by a reduced TLC with normal FEV1/FVC, Spirometry can confirm that FVC is reduced, while FEV1 may be reduced secondarily to a reduction in $\mathrm{FVC}$, or relatively maintains as normal.
As a result, FEV1/FVC is normal or may increase slightly.

The present study show MVV \% was significantly lower in females in comparison to males' patients. This is in accordance with the study done by Budhiraja et $\mathrm{al} ;{ }^{[16]}$ this can be attributed to the fact that the men have bigger lungs for the same height as compared to females. Another contributing factor could be the greater strength of respiratory muscles in males. ${ }^{[17]}$

The present study shows that FEV1\% has the highest specificity and sensitivity among other parameters of spirometry in patients with cervical spinal stenosis since the classification of the severity of obstructive and restrictive impairments based upon the grade of reduction in FEV1 and VC respectively ${ }^{[18]}$ otherwise the categorizing of restrictive impairment stated by ERS(European respiratory society ) in 2005 has been established based on predicted FEV1\% ${ }^{[15]}$, the categorization of both obstructive and restrictive impairment has been recommended by ERS using FEV1 due to easiness compared to ATS method, the reasonable for such a suggestion, in disorders presenting with restrictive defects, is because the FEV1/VC ratio is conserved (normal or increased) and therefore the reduction in FEV1 has been correlated with the analogous reduction in $\mathrm{VC}$.

\section{Conclusion}

The respiratory dysfunction that is established in patients with cervical spinal stenosis usually subclinical not overt defect that compromised respiration, this pulmonary dysfunction is a type of restrictive lung disease since phrenic nerve is affected. . FEVI\% is most essential among other parameters of spirometry in patients with cervical spinal stenosis.

Ethical Clearance: The Research Ethical Committee at scientific research by ethical approval of both environmental and health and higher education and scientific research ministries in Iraq

Conflict of Interest: The authors declare that they have no conflict of interest.

Funding: Self-funding

\section{References}

1. Lebl DR, Bono CM. Update on the diagnosis and management of cervical spondylotic myelopathy. 
JAAOS-Journal of the American Academy of Orthopaedic Surgeons. 2015 Nov 1;23(11):648-60.

2. Haldeman S. The neurodiagnostic evaluation of spinal stenosis. Lumbar spinal stenosis. St. Louis: Mosby. 1992:291-303.

3. McCormack BM, Weinstein PR. Cervical spondylosis. An update. western Journal of Medicine. 1996 Jul;165(1-2):43.

4. Richter M, Kluger P, Puhl W. Diagnosis and therapy of spinal stenosis in the elderly. Zeitschrift fur Orthopadie und ihre Grenzgebiete. 1999;137(6):474-81.

5. Karadimas SK, Gatzounis G, Fehlings MG. Pathobiology of cervical spondylotic myelopathy. European Spine Journal. 2015 Apr 1;24(2):132-8.

6. Howard RS, Thorpe J, Barker R, Revesz T, Hirsch $\mathrm{N}$, Miller D, Williams AJ. Respiratory insufficiency due to high anterior cervical cord infarction. Journal of Neurology, Neurosurgery \& Psychiatry. 1998 Mar 1;64(3):358-61.

7. Ishibe $\mathrm{T}$, Takahashi S. Respiratory dysfunction in patients with chronic-onset cervical myelopathy. Spine. 2002 Oct 15;27(20):2234-9.

8. Yanaka K, Noguchi S, Asakawa H, Nose T. Laminoplasty improves respiratory function in elderly patients with cervical spondylotic myelopathy. Neurologia medico-chirurgica. 2001;41(10):488-93.

9. Ashwell M, Gibson S. Waist to height ratio is a simple and effective obesity screening tool for cardiovascular risk factors: analysis of data from the British National Diet and Nutrition Survey of adults aged 19-64 years. Obesity facts. 2009;2(2):97-103.

10. Bhagavatula ID, Bhat DI, Sasidharan GM, Mishra RK, Maste PS, Vilanilam GC, Sathyaprabha TN. Subclinical respiratory dysfunction in chronic cervical cord compression: a pulmonary function test correlation. Neurosurgical focus. 2016 Jun 1;40(6):E3.
11. Toyoda H, Nakamura H, Konishi S, Terai H, Takaoka K. Does chronic cervical myelopathy affect respiratory function?. Journal of Neurosurgery: Spine. 2004 Sep 1;1(2):175-8.

12. Abdullah SS, Taha JH, Ahmed MH, Abdullah KS. The Influence of Age on Pulmonary Function, A Cross Sectional Study on a Sample of Healthy Iraqi Males and Females Population. InJournal of Physics: Conference Series 2019 Feb (Vol. 1178, No. 1, p. 012027). IOP Publishing.

13. Saliman JA, Benditt JO, Flum DR, Oelschlager BK, Dellinger EP, Goss CH. Pulmonary function in the morbidly obese. Surgery for Obesity and Related Diseases. 2008 Sep 1;4(5):632-9.

14. Flegal KM, Graubard BI, Williamson DF, Gail MH. Cause-specific excess deaths associated with underweight, overweight, and obesity. Jama. 2007 Nov 7;298(17):2028-37.

15. Pellegrino R, Viegi G, Brusasco V, Crapo RO, Burgos F, Casaburi RE, Coates A, Van Der Grinten CP, Gustafsson P, Hankinson J, Jensen R. Interpretative strategies for lung function tests. European respiratory journal. 2005 Nov 1;26(5):948-68.

16. Budhiraja S, Singh D, Pooni PA, Dhooria GS. Pulmonary functions in normal school children in the age group of 6-15 years in north India. Iranian journal of pediatrics. 2010 Mar;20(1):82.

17. Islam $\mathrm{MN}$, Hoque MA, Latif SA, Mollah AH, Hossain MA, Husain MF, Rahman MA, Akhtaruzzaman M, Khan AH, Paul BK, Kundu GK. Peak expiratory flow rate of normal school going children in Mymensingh municipality. Mymensingh medical journal: MMJ. 2013 Jul;22(3):438-43.

18. American Thoracic Society. Lung function testing: selection of reference values and interpretative strategies. Am. Rev. Respir. Dis.. 1991;144:120218. 